\title{
Recurrent Acute Myeloid Leukemia with Multilineage Dysplasia
}

National Cancer Institute

\section{Source}

National Cancer Institute. Recurrent Acute Myeloid Leukemia with Multilineage Dysplasia. NCI Thesaurus. Code C156720.

The reemergence of acute myeloid leukemia with multilineage dysplasia after a period of remission. 